\title{
Experimental Study on the Evaluation and Control of the Ultraviolet Resistance of Sand Stabilized with an Organic Slurry Containing Hydrophilic Polyurethane ${ }^{\dagger}$
}

\author{
English version of the paper published in "Journal of the Society of Materials \\ Science, Japan, 57 (11) : 1167-1172 (2008)”
}

by

Zhiren $\mathrm{Wu}^{*}$, Kentaro Iwashita ${ }^{* *}$, Zhishen $\mathrm{WU}^{* * *}$ and Hirondo InAGAKI ${ }^{* * * *}$

\begin{abstract}
The slurry scattering technique has been widely accepted as a method for fixing moving sand. Using an organic slurry that has high water retention capacity may allow for the growth of vegetation in the desert. However, organic material in the slurry, such as hydrophilic polyurethane, is easily decomposed by ultraviolet irradiation, and ultraviolet rays are extremely strong in the desert. The goal of this paper is to examine, in terms of strength and decomposition rate, the ultraviolet resistance of sand stabilized with an organic slurry containing hydrophilic polyurethane. Adding emulsified asphalt improved the ultraviolet resistance of the stabilized sand. Although all of the asphalt emulsions used in the experiment have similar beneficial effects, the nonionic emulsified asphalt is considered to be one of the best solutions due to its neutrality. Moreover, the ultraviolet resistance of the stabilized sand can be controlled by changing the mixing ratio of the emulsified asphalt. By mixing the emulsified asphalt in the slurry at ratios of $5 \%, 6 \sim 8 \%$, and $9 \%$, the weight loss rate due to ultraviolet irradiation was 1.5 1.8 times, 2.1 5.4 times, and 4.7 18.2 times smaller respectively.
\end{abstract}

Key words : Desert landscape, Organic slurry, Hydrophilic polyurethane, Ultraviolet resistance, Emulsified asphalt

\section{Introduction}

Moving deserts have developed and expanded rapidly in grasslands and urban areas in various parts of the world, causing serious problems such as reduced human living space and local climate change. It is critical to stop blown sand transport and the exposure of plant roots to prevent moving deserts from expanding. The main techniques currently employed to stop sand from being blown in moving deserts involve containing sand dunes by planting trees, laying straw and stone matrices, and constructing layers of hydrophobic grains to some depth below ground. ${ }^{1,2)}$ However, each of these techniques is problematic. Trees require abundant underground water, straw and stone matrices are incapable of fully curtailing wind erosion in high-wind regions, and hydrophobic layers are economically and practically difficult to install in large expanses of desert.

Therefore, authors focused on the sand capping technique with sand stabilizing and sand-blow suppressing agents. The authors also concentrated on developing advanced capping technology that uses organic slurries chiefly composed of hydrophilic polyurethane (PU) as the capping material. ${ }^{1)}$ It is possible to form a thin stabilization layer (typically $5 \sim 50 \mathrm{~mm}$ thick) by spreading the slurry over the sand surface, thereby obtaining a semi-hardened surface that is resistant to wind erosion. As this layer develops a porous morphology, it can retain water and thus enable vegetation to grow in regions that have little underground water, even when subjected to strong wind erosion forces. In a study on the mechanism of sand grain movement, ${ }^{3,4)}$ Kawada et al. found that sand blowing is suppressed by increasing the grain size, density, and water content of the sand.

In this investigation, organic slurry with PU contents ranging from 2 to $7 \%$ is used; the lower limit is based on the required surface strength of the stabilized layer, and the upper limit is based on economic considerations. This composition enables the formation of a porous stabilized layer with sufficient voids for vegetation and high water retention capacity. It also facilitates the improvement of slurry application processes and equipment for seed spraying as a rapid, simple means for growing vegetation. It also does not need to be removed after vegetation has grown, because organic hydrophilic PU decomposes over time in deserts and other regions that are subject to high ultraviolet (UV) radiation levels. However, for the same reason, it is necessary to prevent decomposition before any vegetation has grown. Therefore, to use the slurry effectively, it is critical to control its UV resistance.

In the present study, the UV resistance of sand stabilized by organic slurries with various PU concentrations by performing accelerated UV exposure experiments to determine its endurance time is investigated. The UV resistance by adding an asphalt emulsion to the slurry is

\footnotetext{
$\dagger \quad$ 原稿受理 平成 22 年 6 月 17 日 Received June 17, 2010 (C) 2011 The Society of Materials Science, Japan

* Grad. Sch. Sci. and Eng., Ibaraki Univ., Nakanarusawa, Hitachi, 316-8511 Japan

* $\quad$ Member : Dept. Civ. Eng., Meijo Univ., Tenpaku-ku, Nagoya, 468-8502 Japan

*** Member : Dept. Urb. \& Civ. Eng., Ibaraki Univ., Nakanarusawa, Hitachi, 316-8511 Japan

$* * * * \quad$ JCK Co. Ltd., Imaike, Anjo, 446-0071 Japan
} 
controlled and the stabilized sand surface almost black in color is made. The appropriate mixing ratios of the PU and asphalt emulsions for organic slurry and the type of asphalt emulsion are proposed for the sand stabilization for desert vegetation.

\section{Experimental methods}

\section{1 Materials}

Toyoura standard sand and tap water were used throughout the study. PU in the form of a hydrophilic prepolymer was used as the main component of the organic slurry, due to its excellent hydrolytic, hydrophilic, and soil penetration abilities as well as and its relatively low cost. These properties enable it to be used as a soil stabilizer and a material for preventing water leakage and spurting. ${ }^{5)}$ Four asphalt emulsions ${ }^{6)}$ were selected for the experiments ; they are classified based on their asphalt particle charge state (nonionic, cationic), application category (penetration or mixing), and modification state.

(1) PKR (cationic, penetrating, modified (rubber added))

(2) PK3 (cationic, penetrating, modified)

(3) MK2 (cationic, mixing)

(4) MN1 (nonionic, mixing)

As described in Basis and Practical Techniques of Emulsified Asphalt (Japan Emulsified Asphalt Association), ${ }^{7)}$ cationic asphalt is charge-carrying and acidic, whereas nonionic asphalt is non-charge-carrying and neutral.

\subsection{Test specimens}

The test specimens were $50 \mathrm{~mm}$ in diameter and $50 \mathrm{~mm}$ high. They were prepared by (1) lining a mold $50 \mathrm{~mm}$ in diameter and $100 \mathrm{~mm}$ high with a mold release film, filling the mold with a slight excess of test sand, and tapping the mold lightly to tamp the sand (with a $40 \%$ void ratio as the standard) ; (2) mixing the indicated quantity of asphalt emulsion and water, then mixing the indicated quantity of PU to obtain the organic slurry, and pouring the resulting mixture into the mold in a quantity equivalent to $7.5 \mathrm{~L} / \mathrm{m}^{2}$; and (3) allowing the charged mold to stand for approximately $30 \mathrm{~min}$ to obtain a hardened test specimen weighing $150 \pm 1 \mathrm{~g}$. In experiments conducted in the model region at Qinghai Lake reported by the NEDO project ${ }^{9)}$ the application volume was $3 \mathrm{~L} / \mathrm{m}^{2}$ due to the hardness of the stabilized sand and economic considerations ; this amount resulted in an average penetration depth of approximately $20 \mathrm{~mm}$. In the present study, the application volume was increased so that the slurry penetrated to the bottom of the test specimens. As the penetration depth was the full $50 \mathrm{~mm}$ height of the test specimen and the volume per square meter was $50 \mathrm{~L}$ with an initial void volume of $20 \mathrm{~L}$, subtracting the volume of the organic material in the slurry charged portion $(7.5 \mathrm{~L} \times 5 \%=0.375 \mathrm{~L}$ in the case of $5 \%$ hydrophilic polyurethane mass content) left a residual void volume of $19.625 \mathrm{~L}$ and thus a void ratio of $39.25 \%$ in the final test specimen. The two experimental parameters were (1) the type of asphalt emulsion and (2) the emulsified asphalt content. Table 1 shows the PU and asphalt emulsion content of each organic slurry used to produce the test specimens, and Figure 1 shows typical test specimens.

Table 1 Summary of test soil stabilized with hydrophilic polyurethane and emulsified asphalt

\begin{tabular}{|c|c|c|c|}
\hline $\begin{array}{c}\text { Sign of } \\
\text { specimen }\end{array}$ & $\begin{array}{c}\text { Mass content } \\
\text { of hydrophilic } \\
\text { polyurethane } \\
(\%)\end{array}$ & $\begin{array}{c}\text { Type of } \\
\text { emulsified } \\
\text { asphalt }\end{array}$ & $\begin{array}{l}\text { Mass content } \\
\text { of emulsified } \\
\text { asphalt (\%) }\end{array}$ \\
\hline P3\%-A0\% & 3 & None & None \\
\hline $\mathrm{P} 5 \%-\mathrm{A} 0 \%$ & 5 & None & None \\
\hline P5\%-APR2\% & 5 & PKR & 2.0 \\
\hline P5\%-APR2.5\% & 5 & PKR & 2.5 \\
\hline P5\%-APR3.3\% & 5 & PKR & 3.3 \\
\hline P5\%-APR5\% & 5 & PKR & 5.0 \\
\hline P5\%-APR6\% & 5 & PKR & 6.0 \\
\hline P5\%-APR7\% & 5 & PKR & 7.0 \\
\hline P5\%-APR8\% & 5 & PKR & 8.0 \\
\hline P5\%-APR9\% & 5 & PKR & 9.0 \\
\hline P5\%-APR10\% & 5 & PKR & 10.0 \\
\hline P5\%-APK5\% & 5 & PK3 & 5.0 \\
\hline P5\%-APK6\% & 5 & PK3 & 6.0 \\
\hline P5\%-APK $7 \%$ & 5 & PK3 & 7.0 \\
\hline P5\%-APK $8 \%$ & 5 & PK3 & 8.0 \\
\hline P5\%-APK9\% & 5 & PK3 & 9.0 \\
\hline P5\%-AMK5\% & 5 & MK2 & 5.0 \\
\hline P5\%-AMK6\% & 5 & MK2 & 6.0 \\
\hline P5\%-AMK7\% & 5 & MK2 & 7.0 \\
\hline P5\%-AMK $8 \%$ & 5 & MK2 & 8.0 \\
\hline P5\%-AMK9\% & 5 & MK2 & 9.0 \\
\hline P5\%-AMN5\% & 5 & MN1 & 5.0 \\
\hline P5\%-AMN6\% & 5 & MN1 & 6.0 \\
\hline P5\%-AMN7\% & 5 & MN1 & 7.0 \\
\hline P5\%-AMN8\% & 5 & MN1 & 8.0 \\
\hline P5\%-AMN9\% & 5 & MN1 & 9.0 \\
\hline $\mathrm{P} 2 \%-\mathrm{AMN} 7 \%$ & 2 & MN1 & 7.0 \\
\hline P3\%-AMN7\% & 3 & MN1 & 7.0 \\
\hline $\mathrm{P} 4 \%-\mathrm{AMN} 7 \%$ & 4 & MN1 & 7.0 \\
\hline P6\%-AMN7\% & 6 & MN1 & 7.0 \\
\hline
\end{tabular}




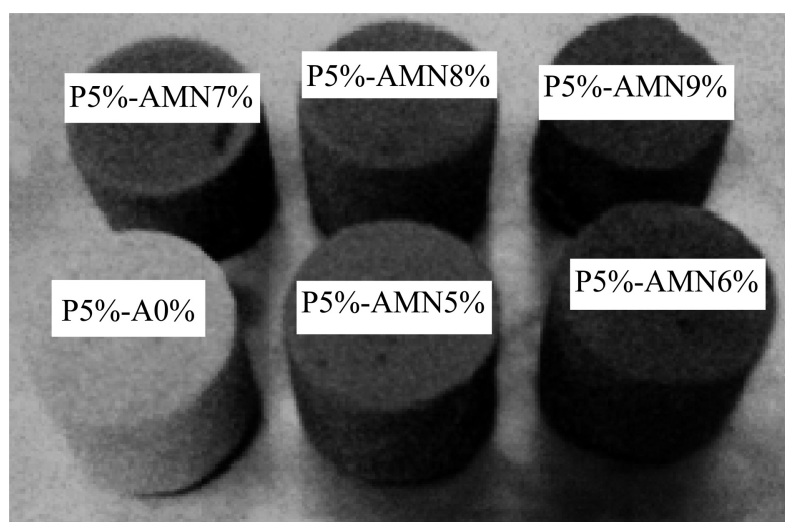

Fig. 1 Test soil stabilized with hydrophilic polyurethane and emulsified asphalt, MN1.

\section{3 UV irradiation and water spray}

The accelerated weathering tests were performed with a CO. FO. ME. GRA high-energy xenon weatherometer (Solarbox 1500e). ${ }^{8)}$ As a variable-intensity, high-light-energy instrument, it was capable of providing an irradiance of $1000 \mathrm{~W} / \mathrm{m}^{2}$, which is higher than other weatherometers, making it ideal for the accelerated conditions used in this study. Figure 2 shows a test specimen in place on the test instrument. The irradiance was $1,000 \mathrm{~W} / \mathrm{m}^{2}$ and the initial air temperature was $50^{\circ} \mathrm{C}$ (it stabilized at $54^{\circ} \mathrm{C}$ after approximately $10 \mathrm{~min}$ of UV irradiation). To accelerate decomposition, irradiation was stopped every 24 hours and $2 \mathrm{~L} / \mathrm{m}^{2}$ of water was sprayed. As described in the Technical report of New Energy and Industrial Technology Development Organization ${ }^{9)}$ concerning the China Institute of Water Resources and Hydropower Research in Qinghai Province, the annual UV insolation of the moving desert at Qinghai Lake in China is $607 \sim 720 \mathrm{~kJ} / \mathrm{cm}^{2}$, which when divided by 12 gives a monthly UV insolation of $50.6 \sim 60.0 \mathrm{~kJ} / \mathrm{cm}^{2}$. With the irradiance of $1,000 \mathrm{~W} / \mathrm{m}^{2}$ used in this study, the daily irradiation is $8.64 \mathrm{~kJ} / \mathrm{cm}^{2}$, and 140.6 166.7 hours corresponds to one month of insolation in a moving desert.

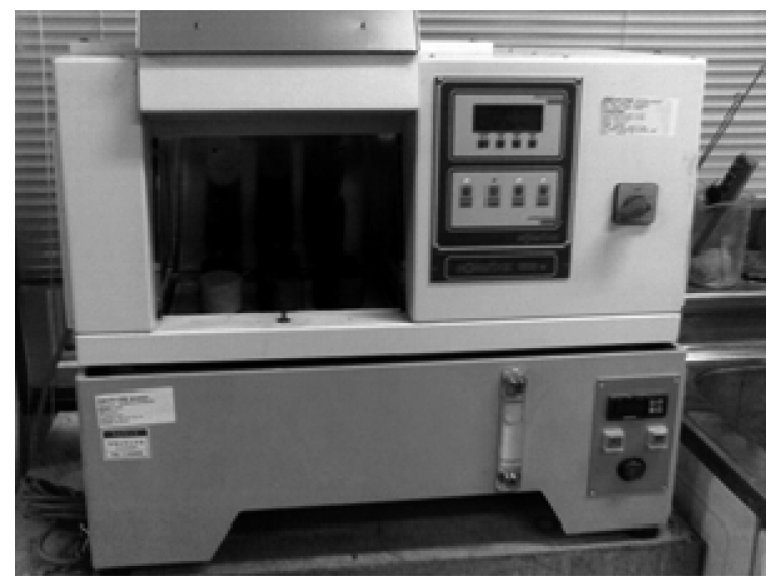

Fig. 2 Accelerated ultraviolet irradiation testing machine (Solarbox1500e). ${ }^{8)}$

\section{4 Measurements and evaluation criteria}

In each trial, the weatherometer was stopped every 24 hours, sand that had been accumulated on the test specimen surface was removed with an electrostatic precipitator, and the specimen weight loss was calculated. The initial weight of each specimen was adjusted to $150 \mathrm{~g}$ at the time of preparation, and the weight loss was divided by this value to obtain the weight loss ratio, which was one of the evaluation criteria. The surface hardness of each specimen was also measured three times with a Yamanaka soil hardness tester and the average was obtained and used as a second evaluation criterion.

\section{Experimental results and discussion}

\section{1 UV resistance with no asphalt emulsion added to organic slurry}

Figures 3 and 4 show the relationship from the accelerated UV irradiation trials between the weight loss and the irradiation time for the specimens stabilized by organic slurry containing PU without (P3\%-A0\% and P5\%-A0\%) and

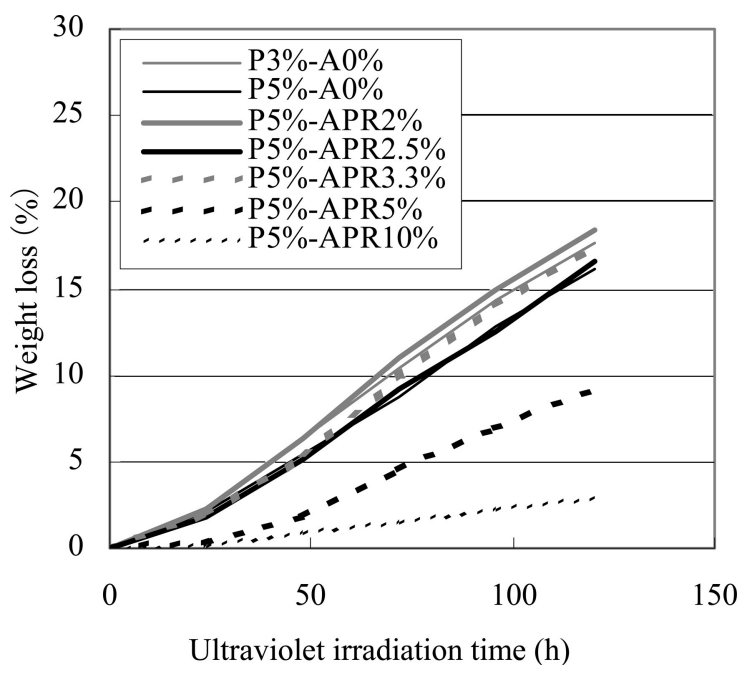

Fig. 3 Relationships between ultraviolet irradiation time up to 125 hours and weight loss of specimens with PKR.

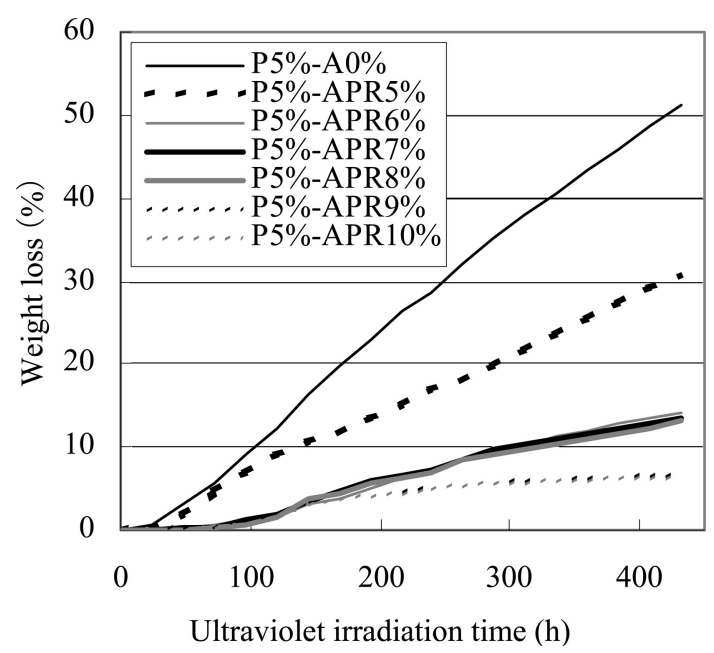

Fig. 4 Relationships between ultraviolet irradiation time up to 424 hours and weight loss of specimens with PKR. 
with PKR asphalt emulsion. As measured after each irradiation interval, the specimen weight loss rate of the $\mathrm{P} 3 \%$ A0\% formulation was approximately constant after approximately 25 hours of irradiation, which indicates an approximately constant rate of PU decomposition. The $\mathrm{P} 5 \%-\mathrm{A} 0 \%$ formulation has almost the same weight loss rate as the $\mathrm{P} 3 \%-\mathrm{A} 0 \%$ formulation, indicating that an increase of the PU content within a range of $3 \sim 5 \%$ in the organic slurry has little effect on the UV decomposition rate. As shown in Figure 4 for P5\%-A0\%, a substantial amount of PU decomposition, as indicated by the specimen weight loss of $19.7 \%$, occurred over a UV irradiation period of 168 hours, which is equivalent to one month in a moving desert. This loss clearly indicates that UV irradiation will cause substantial decomposition of the PU in this formulation within approximately one month in a moving desert.

\section{2 UV resistance with asphalt emulsion added to organic slurry}

As shown in Figure 3, adding PKR asphalt emulsion at contents of up to $3.3 \%$ in the organic slurry formulation had little effect on the UV resistance, but an addition of $5 \%$ substantially increased the UV resistance and a 10\% addition resulted in another sharp increase. As shown in Figure 4, the UV resistance as indicated by the sample weight loss compared to that with no PKR addition was 1.8 times higher with 5\% PKR, 3.9 times higher with 6 8\% PKR, and 7.7 times higher with 9\% and 10\% PKR.

Figure 5 shows the relationship between the reduction of the Yamanaka soil hardness index and the UV irradiation time. The hardness of the specimens prior to UV irradiation, as measured with an Yamanaka soil hardness tester, were $21 \sim 23 \mathrm{~mm}$ with $0 \% \mathrm{PKR}, 23 \sim 24 \mathrm{~mm}$ with 5 6\% PKR, and 26 28 mm with 7 10\% PKR indicating that the hardness index increases as the asphalt emulsion content increases. The surface hardness was found to decrease as the irradiation time increased. The surface hardness was controlled to

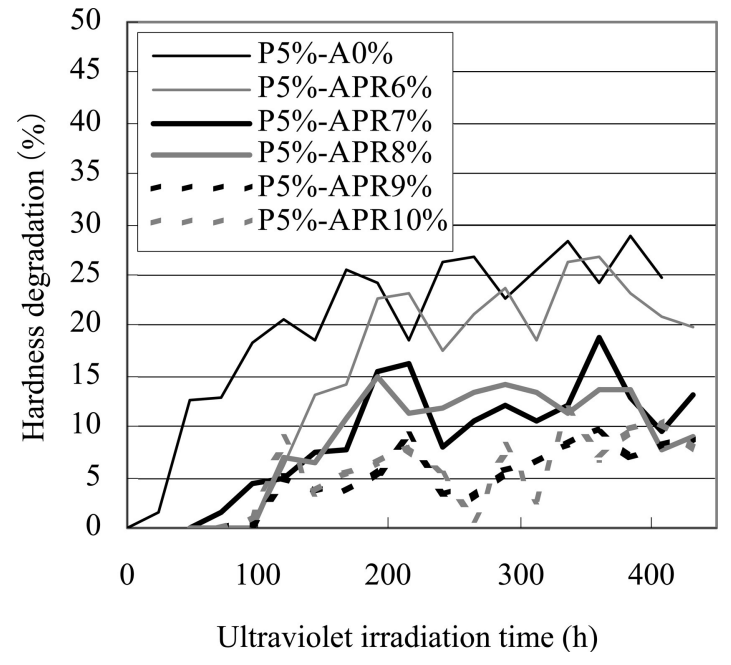

Fig. 5 Relationships between ultraviolet irradiation time and hardness degradation of specimens with PKR. approximately $50 \%$ by using 7 8\% PKR, whereas it was controlled to approximately $30 \%$ with using $9 \sim 10 \%$ PKR. However, because they were rather small, the specimens tended to break into two pieces when the surface hardness decreased considerably, making it impossible to accurately measure the surface hardness. The surface hardness values obtained using small specimens are not appropriate as a standard for evaluating long-term UV irradiation resistance.

Figures 6,7 , and 8 show the relationship between the UV irradiation time and the weight loss of specimens composed of an organic slurry of PU and an asphalt emulsion of PK3, MK3 or MN1. Table 2 shows the weight loss for all four types of asphalt emulsion after 168 hours of UV irradiation. For each asphalt emulsion type, a specimen with $\mathrm{P} 5 \%-\mathrm{A} 0 \%$ was tested in addition to specimens with various asphalt emulsion contents. The test results for the $\mathrm{P} 5 \%-\mathrm{A} 0 \%$ specimens revealed a variation of approximately $5 \%$ in the weight loss ratio, confirming the

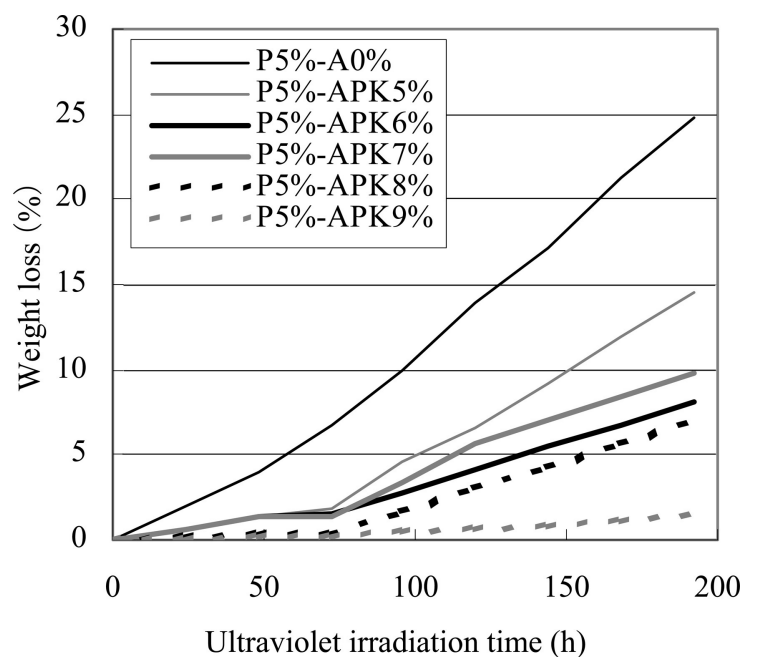

Fig. 6 Relationships between ultraviolet irradiation time and weight loss of specimens with PK3.

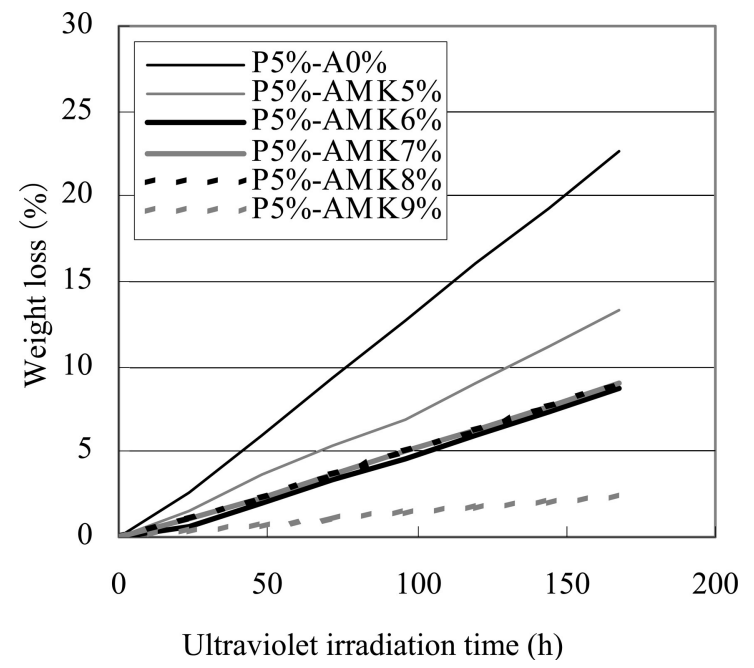

Fig. 7 Relationships between ultraviolet irradiation time and weight loss of specimens with MK2. 


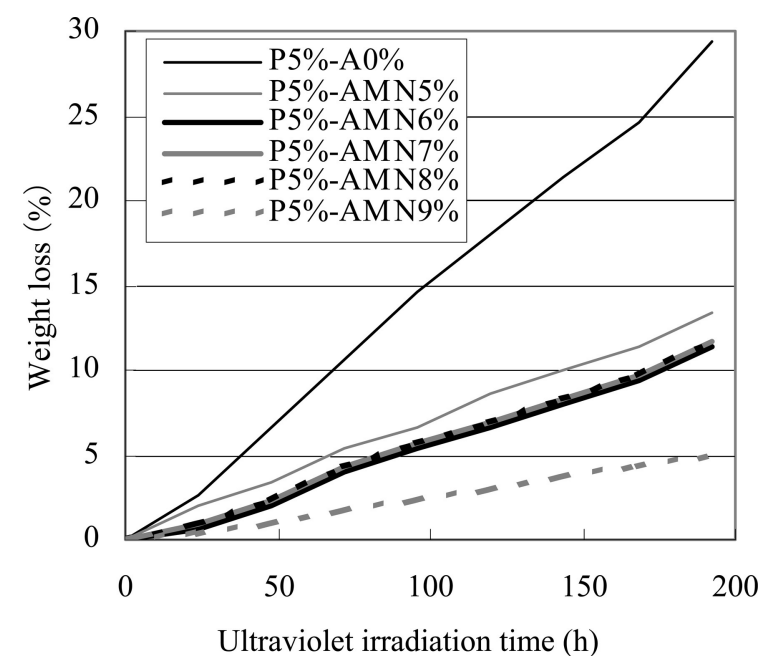

Fig. 8 Relationships between ultraviolet irradiation time and weight loss of specimens with MN1.

repeatability of the experiment. The weight loss rate remained approximately constant throughout irradiation for all three asphalt emulsion types. In all cases, the rate was moderately reduced by the addition of $5 \%$ asphalt emulsion, more strongly reduced with a $6 \sim 8 \%$ addition, and sharply curtailed by a $9 \%$ addition, indicating a marked increase of UV resistance with increasing asphalt emulsion content. As shown in Table 2, the weight losses after 168 hours of irradiation, which corresponds to one month in amoving desert, were $11.2 \sim 13.3 \%$ with $5 \%$ asphalt emulsion, $3.7 \sim 9.7 \%$ with $6 \sim 8 \%$, and $1.1 \sim 4.3 \%$ with $9 \%$, representing reductions to $56 \sim 69 \%, 19 \sim 48 \%$, and $6 \sim 21 \%$, respectively, of the values obtained for PU alone. This reveals that asphalt emulsion can both substantially increase the UV resistance of the organic slurry and allow considerable control of the resistance level. However, it must be noted that the limited time available for the present study permitted only short-term testing ; to verify the above findings regarding the UV resistance, it will be important to perform longer-term testing in greater detail in future studies. Figures 9 to 11 show the relationship between the reduction of the Yamanaka surface hardness index and the UV irradiation time for each type of asphalt emulsion. These results confirm that, regardless of the asphalt

Table 2 Weight loss of specimens at ultraviolet irradiation time of 168 hours.

\begin{tabular}{|c|c|c|c|c|c|}
\hline \multirow{2}{*}{$\begin{array}{c}\text { Type of } \\
\text { emulsified } \\
\text { asphalt }\end{array}$} & \multicolumn{5}{|c|}{ Content of emulsified asphalt (\%) } \\
\cline { 2 - 6 } & 5 & 6 & 7 & 8 & 9 \\
\hline PKR & 11.2 & 3.7 & 4.7 & 4.4 & 3.7 \\
\hline PK3 & 11.9 & 6.8 & 8.4 & 5.7 & 1.1 \\
\hline MK2 & 13.3 & 8.7 & 9.0 & 9.0 & 2.3 \\
\hline MN1 & 11.3 & 9.3 & 9.7 & 9.7 & 4.3 \\
\hline
\end{tabular}

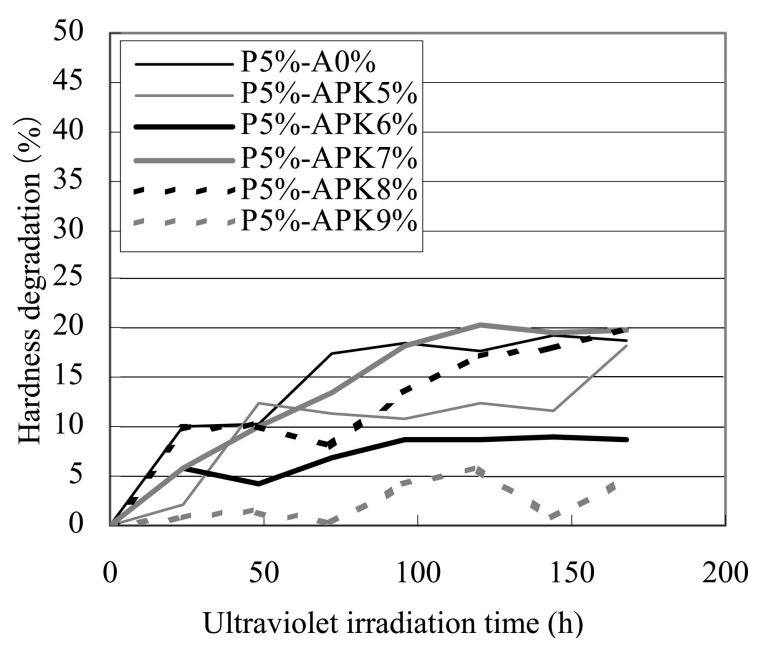

Fig. 9 Relationships between ultraviolet irradiation time and hardness degradation of specimens with PK3.

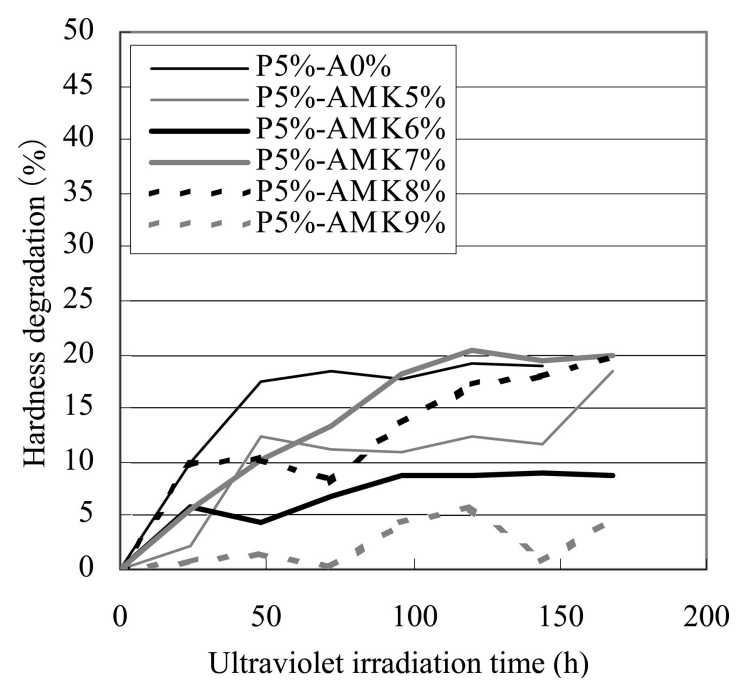

Fig. 10 Relationships between ultraviolet irradiation time and hardness degradation of specimens with MK2.

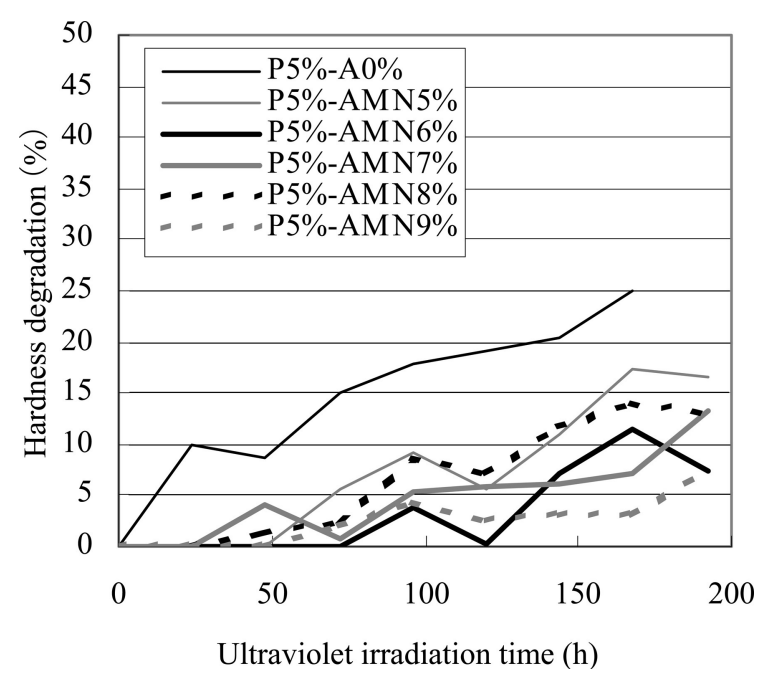

Fig. 11 Relationships between ultraviolet irradiation time and hardness degradation of specimens with MN1. 
emulsion type, the surface hardness tended to decrease as the UV irradiation time increased, and that increasing the asphalt emulsion content apparently reduces the rate of reduction in the surface hardness. However, as noted in Section $\mathbf{3 . 2}$, the small specimens tended to break in two when there was a large reduction, making it impossible to accurately measure this quantity.

\section{3 Proposed mixing ratios and asphalt emulsion types for sand capping}

The above results clearly demonstrate that the type of asphalt emulsion does not greatly influence the UV resistance. Consequently, the use of an asphalt emulsion (such as MN1 in this study) that carries no electric charge and is chemically neutral and nonionic will be preferable in actual applications, because it will facilitate the addition of plant seeds and fertilizers to the organic slurry and thus enable more efficient greening and sand stabilization in moving deserts.

The results also reveal that adding asphalt emulsion to the organic slurry not only enhances the UV resistance but also enables it to be controlled by the exact addition ratio, which would presumably result in sand disaggregation after an appropriate stage of plant growth and would thus be advantageous for subsequent plant growth. In this light, further studies are required on plant growth rates and the optimization of the UV resistance duration for their effective growth, which may advance desert greening technology. The present study was limited to a short-term investigation due to time constraints ; longer-term investigations involving more detailed experiments are essential.

\section{Conclusions}

The present study is an experimental assessment of sand stabilization by organic slurry containing hydrophilic PU and demonstrated that UV resistance can be controlled by adding asphalt emulsion to the slurry. An optimum capping material is proposed and consists of organic slurry with the appropriate PU content and additional asphalt emulsion of the appropriate type and mixing ratio. The following findings were obtained :

(1) Sand specimens stabilized with PU alone exhibited a weight loss of $19.7 \%$ after 168 hours of irradiation (equivalent to one month in the moving desert region at Qinghai Lake, China) in accelerated UV irradiation tests. This clearly demonstrates that considerable decomposition of hydrophilic PU would occur even with UV exposure corresponding to just one month in a moving desert.

(2) Adding asphalt emulsion to the stabilizing slurry reduced the sand specimen weight losses by $56 \sim 69 \%$ at
5\% addition, $19 \sim 48 \%$ at $6 \sim 8 \%$ addition, and $6 \sim 21 \%$ at $9 \%$ addition. Adding asphalt emulsion not only substantially increases the UV resistance of the slurry, but also gives considerable control over the level of UV resistance.

Time constraints limited the present study to shortterm experimental investigations ; in the long term, more detailed investigations will be necessary. Further studies are under consideration in the hope that they will advance greening technology through the modification of hydrophilic polyethylene resins, increased asphalt emulsion addition, and other methods of heightening the level of UV resistance, along with related investigations into plant growth and development to ascertain the optimum techniques for efficient desert vegetation.

This study was performed with financial assistance from the New Energy and Industrial Technology Development Organization (NEDO). The authors also gratefully acknowledge the provision of hydrophilic polyurethane by Toho Chemical Industry Co. Ltd. and asphalt emulsions by Nichireki Co., Ltd.

\section{References}

1) Chemical Society of Japan, "Desertification prevention research as interdisciplinary science”, Chemistry \& industry, Vol.61, No.2, pp.103-107 (2008)

2 ) K. Yoshikawa, N. Yamanaka and N. Ohte, "Nature and vegetation in the dry areas", (2004) Kyoritsu shuppan co., ltd.

3 ) Y. Kawata and Y. Tsuchiya, "Influence of water content on the threshold of sand movement and the rate of sand transport in blown sand", Journal of the Japan Society of Civil Engineers, No.249, pp.95-100 (1976).

4) Y. Tsuchiya and Y. Kawata, "Mechanism of motion of sand grains by wind (1) -Experiments on the initiation for movement of sand grains-", Annuals of Disaster Prevention Research Institute, Kyoto University, No.13, pp.217-232 (1970).

5 ) TOHO Chemical Industry, "Technical manual of Hydrophilic polyurethane", (2007).

6 ) NICHIREKI co. 1td., "Technical manual of emulsified asphalt" (2007).

7 ) CO. FO. ME. GRA. s.r.l. co. 1td., Italy, "Instruction manual of Solarbox1500e (Document code : 06520104E-1/1999 and 06520101.1E-1/2001)”, (1999 and 2001).

8 ) Japan emulsified asphalt association, "Basis and Practical techniques of emulsified asphalt”, (2006).

9) Institute of water resources and hydropower of Qinghai province, Technical report of New Energy and Industrial Technology Development Organization (NEDO), (2008). 